2 
JAN KNOPF

\title{
Geschichten zur Geschichte
}

\author{
KRITISCHE TRADITION \\ DES »VOLKSTÜMLICHEN《 IN DEN KALENDER- \\ Geschichten Hebels und Brechts
}

\author{
MCMLXXIII \\ J. B. Metzlersche VerlagsbuchHandlung


Die in [ ] erscheinenden Zahlen verweisen auf die Anmerkungen

ISBN 978-3-476-00266-2

ISBN 978-3-476-03016-0 (eBook)

DOI 10.1007/978-3-476-03016-0

(C) Springer-Verlag GmbH Deutschland 1973

Ursprünglich erschienen bei J. B. Metzlersche Verlagsbuchhandlung und Carl Ernst Poeschel Verlag GmbH in Stuttgart 1973

D 7 Göttinger philosophische Dissertation 
Meinem Vater 


\section{Inhaltsverzeichnis}

EINLEITUNG . . . . . . . . . . . . . . . . . 1

Bertolt Brechts Fragen eines lesenden Arbeiters . . . . . . 1

Zur Sprache monumentalischer Historie . . . . . . . . 9

Die Fragen innerhalb der Kalendergeschichten . . . . . . 12

Zur Frage des Definierens . . . . . . . . . . . . 15

I. Tradition und Geschichte . . . . . . . . . . 22

1. Definitionen . . . . . . . . . . . . . . . 22

2. Grimmelshausens Kalendergeschichten . . . . . . 35

3. Grimmelshausens Ewig-währender Calender . . . . 45

Hinweise zur Anordnung . . . . . . . . . . . 46

Das große Spatium . . . . . . . . . . . . . 50

4. Practica . . . . . . . . . . . . . 53

II. Geschichte als Geschichten . . . . . . . . 69

1. Nachweise bei Hebel . . . . . . . . . . . . 69

Der rheinländische Hausfreund . . . . . . . . . . . 69

Integration der Kalenderchronologie: Unverhofftes

Wiedersehen. . . . . . . . . . . . . . 75

Humanisierung des Großen: Kaiser Napoleon und die

Obstfrau in Brienne . . . . . . . . . . . . 81

Rationalität und Aufklärung: Eine sonderbare Wirtszeche . . . . . . . . . . . . . . . . . 83

Die Chronik: Unglück der Stadt Leiden . . . . . . 90

Verknüpfung von Kalender und Geschichte . . . . 98

2. Nachweis bei Brecht . . . . . . . . . . . 109

Der Fall Frau B. und sein Berichterstatter . . . . 109

III. ENTtÄUsChUNGEN . . . . . . . . . . . . . 123

Die Erkenntnis des Bekannten . . . . . . . . . 123

1. Verheimlichung der Welt: Reimmichl . . . . . 138

2. Ewigkeit in der Zeit: Alban Stolz . . . . . . . . 146

3. Praktikable Weltbilder: Bertolt Brecht . . . . . 164 


\section{Inhaltsverzeichnis}

4. Ist der Mensch ein wunderliches Geschöpf: Johann Peter Hebel . . . . . . . . . . . . . . 179

IV. SPRACHFORMELN UND EINGREIFENDE SÄTZE . . . . . 186

1. Sprichwörter . . . . . . . . . . . . . . . 186

2. Enttäuschung der sprichwörtlichen Welt . . . . . 200

3. Die Einübung des Ungehorsams bei Hebel . . . . . 212

4. Praktikable Theorien: Bertolt Brechts Kalender-

Gedichte . . . . . . . . . . . . 230

EPILOG . . . . . . . . . . . . . . . 260

Der abstrakte Mensch . . . . . . . . . . . 260

Quellennachweise, ANMERKungen, ExkURSe . • • . • . 268

LITERATUR-VERZEICHNIS . . . . . . . . . . . . . 321

REgISTER . . . . . . . . . . . . . . . 333 
Als wir ihn aber erschlagen hatten

Richteten wir ihn zu, daß er sein Gesicht verlor

Durch die Spuren unserer Fäuste.

Also machten wir ihn unkenntlich

$\mathrm{Daß}$ er keines Menschen Sohn sei.

Bertolt BREChT

Vom UnBeKanNTEN Soldaten 